\title{
El Museo del Barrio reabre con un mensaje sobre el poder político y artístico "latinx"
}

DOI: http://dx.doi.org/10.5377/koot.v0i10.6696 URI: http://hdl.handle.net/11298/779

\author{
Jesús García \\ Periodista \\ dedicado a la literatura y el cine \\ jesus.garcia@eldiariony.com
}

\section{Resumen}

El Museo del Barrio -ubicado en una de las zonas emblemáticas para los hispanos del Alto Manhattan o El Barrio- reabre, después de una extensa renovación con una exhibición colectiva de fotografías y hace una retrospectiva de la obra de Liliana Porter.

Palabras clave: Museos; Actividades de los museos; Museografía; Arte y fotografía.

\begin{abstract}
Approaching its 50th anniversary and after a year closed for renovations, El Museo del Barrio reopens with a Liliana Porter retrospective and a photo exhibit.

In this article published by El Diario New York, Jesús García reports how the phrase that empowered the feminist movement in the 1960s and '70s, "the personal is political," takes on new meaning during the reopening of El Museo del Barrio, where a cluster of artists explore public spaces turned private and the way they empower Hispanics in the United States. (VoicesOfNY).
\end{abstract}

Keywords: Museums, activities of the museums, museography, art and photography. 


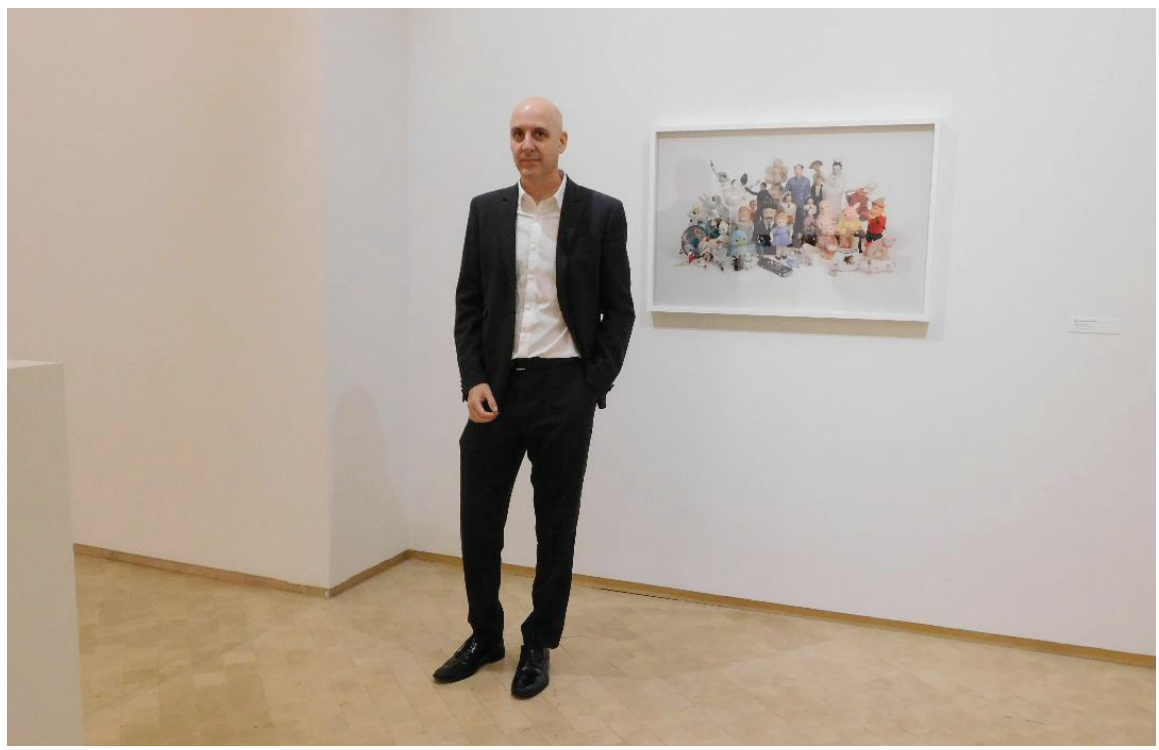

El director de El Museo, Patrick Charpenel, destaca la colaboración del recinto con otros museos. Fotografía Jesús García

La frase que empoderó al movimiento feminista en los años sesenta y setenta del siglo pasado, "lo personal es político", cobra un nuevo sentido durante la reapertura del Museo del Barrio con una colección de artistas que explora el espacio público vuelto privado y como esto empodera a los hispanos en Estados Unidos.

En la misma ruta de discurso, el recinto despliega el trabajo de Liliana Porter, "Other situations" ("Otras situaciones"), una retrospectiva que se suma a las exhibiciones que destacan el trabajo de las artistas hispanas de renombre.

"Es fundamental reabrir haciendo un ejercicio de memoria y sobre todo en espacios donde las comunidades latinas siempre se mueven", explica Patrick Charpenel, director del museo, quien destaca la exposición de Porter, así como "Down These Mean Streets: Community and Place in Urban Photography" ("Abajo estas calles malas: comunidad y espacio en la fotografía urbana") de varios artistas, integrados en un todo por Carmen Ramos, curadora jefe adjunto del museo y curadora de Arte Latino del Smithsonian American Art Museum (SAAM).

"Liliana Porter es una de las artistas que realmente se desarrollo aquí... llegó en los años sesenta", dice Charpenel. "Ella tiene un lazo inusitable, un sentido peculiar... confundiendo siempre la ficción con la realidad". 


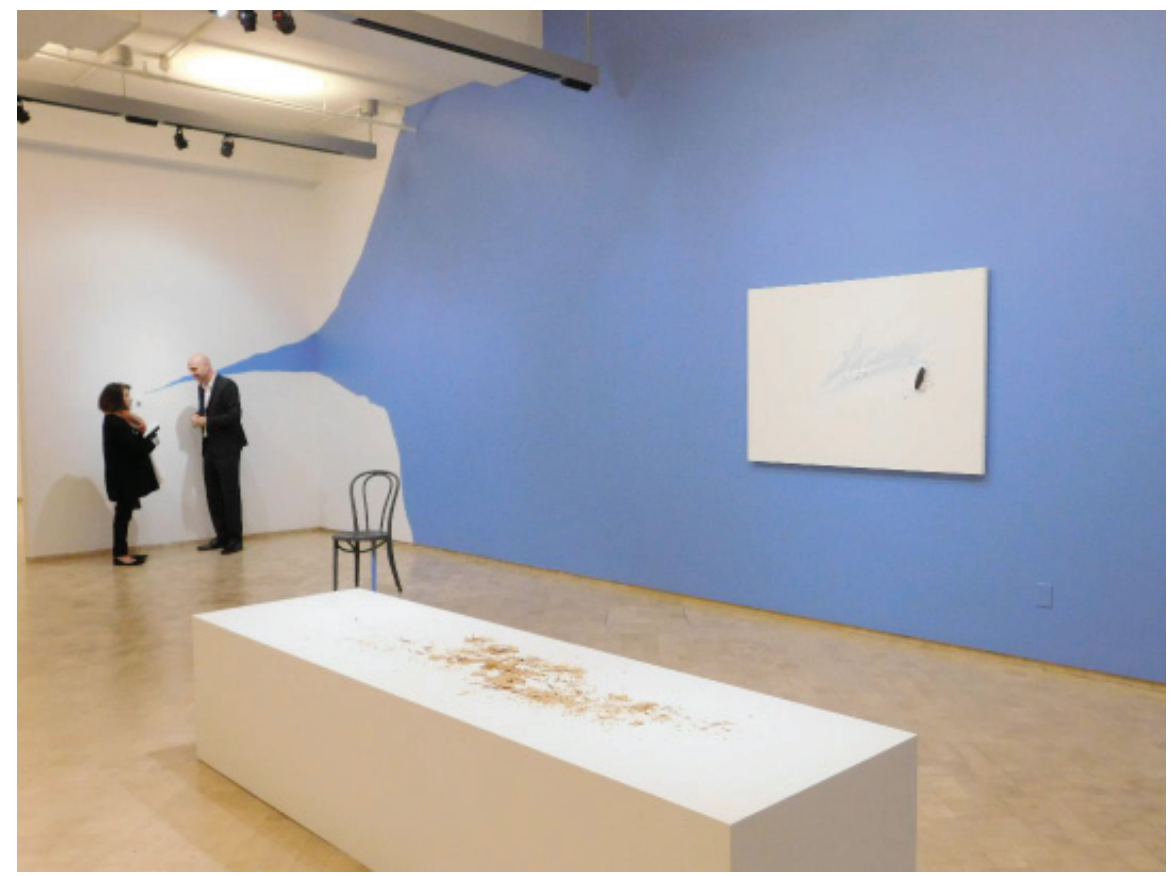

El Museo del Barrio reabre sus puertas. Fotografía Jesús García

\section{Larga remodelación}

El Museo reabre después de casi un año de remodelación, pero lo hará por partes, ya que su auditorio, con capacidad para 600 personas, sigue en restauración, porque se mantendrá su espíritu, con sus murales, pero "se alejará del pasado para traerlo al siglo XXI", explica el director del recinto. La fecha para el corte del listo está pendiente, pero Charpenel afirma que será un escenario que integrará "todas las expresiones artísticas".

Para el 50 aniversario del museo se prepara una publicación que dará entrada a una nueva área del institución con obras en inglés y español que narrará la historia del arte latino en EE.UU., no sólo en Nueva York.

Las primeras muestras, destaca Charpenel, integran trabajos de otros museos, porque "ningún recinto debe replegarse", afirma, al tiempo de que debe impulsar a sus propios artistas y enriquecer sus colecciones.

\section{Las calles de todos}

La exposición fotográfica "Down These Mean Streets: Community and Place in Urban Photography" incluye artistas de California, Nueva York, Nueva 


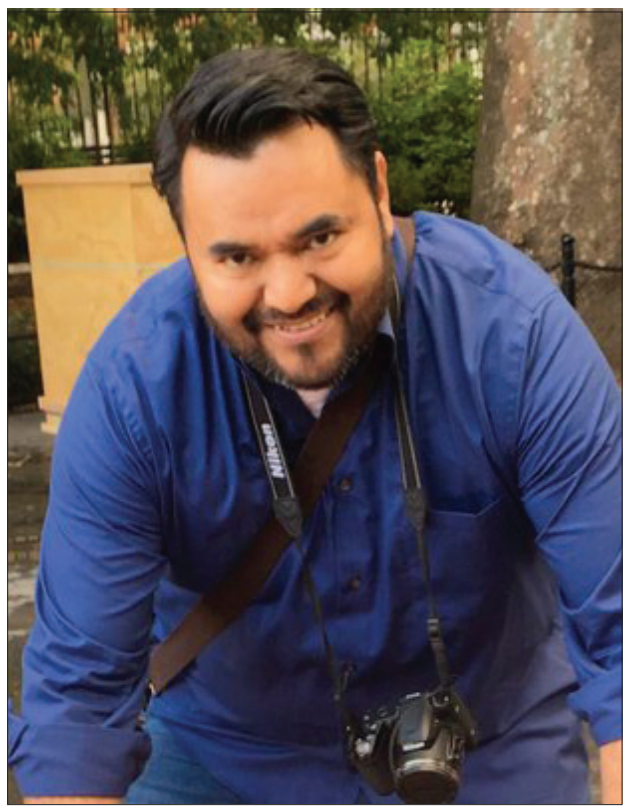

Jesús García

Jersey, Puerto Rico y Texas, que muestran espacios públicos californianos $\mathrm{y}$ neoyorquinos.

Ramos, la curadora, destaca que el nombre de la exhibición se retomó del libro de Piri Thomas, "Down Mean Streets", donde el autor narra su difícil infancia en Harlem. Las obras fueron "prestadas" por el Smithsonian.

"Hemos estado incrementando la colección de latinos, desde 2010, que cuando comencé ahí... la mayoría de las fotografías son parte de esa colección que comenzamos hace muchos años y pone en un mismo espacio a 10 artistas latinos, de los años 60, 70, 80 y hasta ahora", explica Ramos.

El espectador encontrará espacios comunes, como las bodegas de Harlem, y rostros de la diversidad hispana, algunos expuestos tal cual como fueron captados por la lente, pero otros "alterados", como el trabajo de Manuel Acevedo, nacido en Newark, NJ. "Él tomó la fotografía, luego intervino esa imagen... la colocó en el espacio y volvió a tomarla... es decir, es una intervención del espacio, sin alterar la imagen", explica Ramos al destacar "Espacios alterados \#7", como una de las obras de mayor relevancia. 


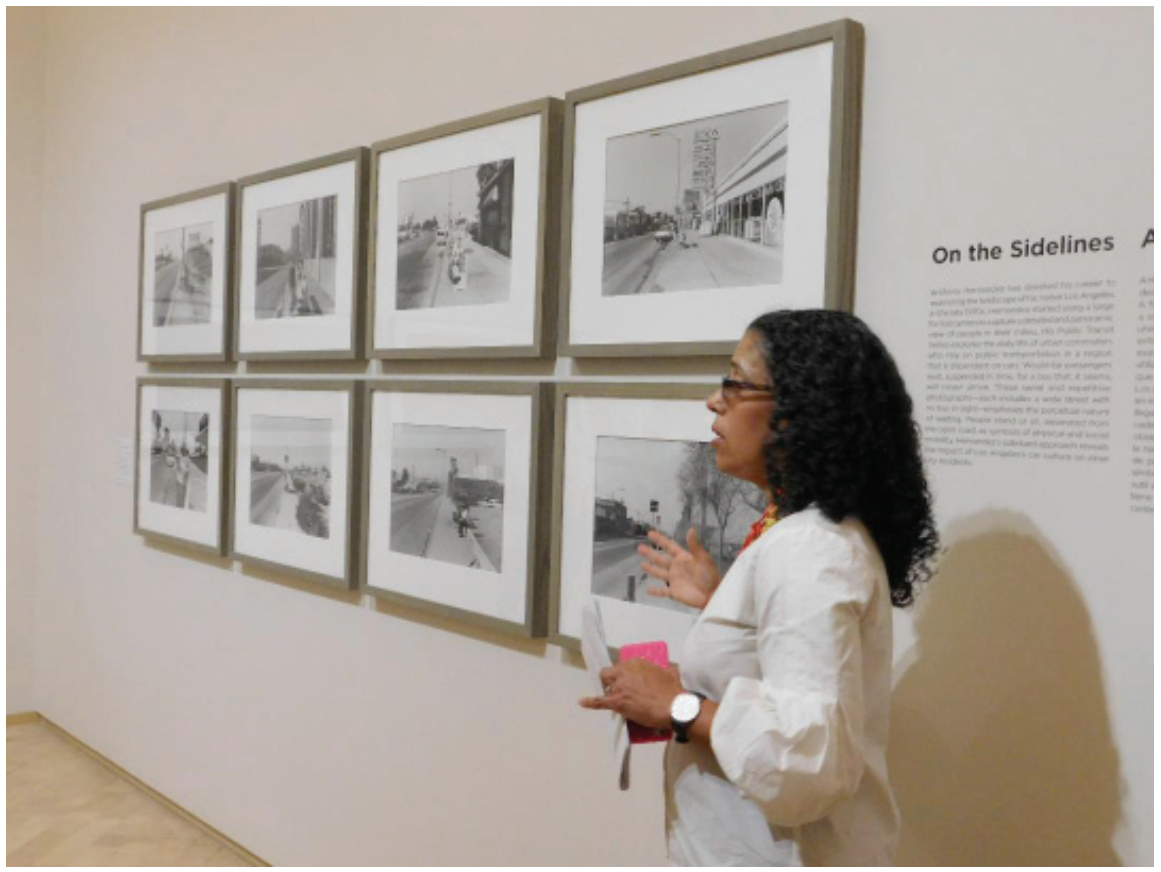

La curadora Carmen Ramos explica parte de la exposición colectiva con 10 artistas latinos. Fotografía Jesús García

El recorrido es un viaje al pasado, pero con un claro recordatorio del presente sobre la comunidad hispana y su apropiación del espacio.

\section{La "otras situaciones"}

La artista Liliana Porter, nacida en Argentina, residente de Nueva York desde hace 30 años, reinventa su trabajo en la exhibición "Other situations", donde micro mundos -que podrían pasar desapercibidos por el espectador- originan elementos de grandes dimensiones.

"Diferentes puntos de vista y actitudes sobre quiénes somos, el contexto, creo que el mundo del artista, su obra, ayuda a pensar", expresa Porter, quien reconoce que una de sus obras favoritas es el dibujo de una mano de los años setenta que integró en un círculo perfecto recién dibujado.

Humberto Moro, curador de SCAD Museum of Art (SCAD), lideró la integración de las obras en un discurso que incluye videos co-dirigidos por Ana Tirsconia, con quien Porter presentará una obra teatral en The Kitchen. 
"Son sus ideas, relacionadas a su arte, el espacio, las situaciones, la representación, la disrupción", explica Tirsconia. "Cada video es una nueva pieza... exploran la obra de Liliana desde los años sesenta".

La reapertura y exhibiciones del museo tuvo una importante colaboración de la Fundación Jaques \& Natasha Gelman, la exrepresentante Melissa MarkViverito y el Bernie Stadiem Endowrment Fund.

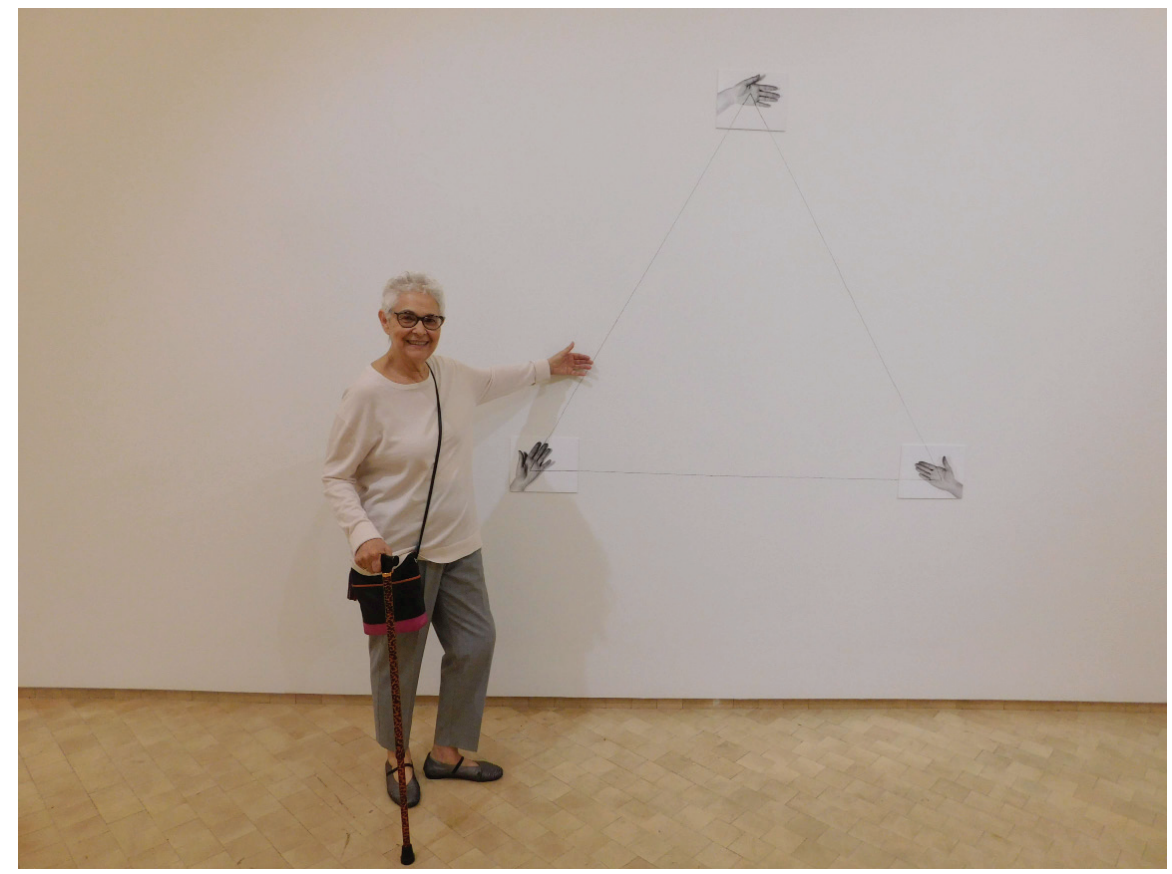

La artista Liliana Porter utiliza obras de hace años para unirlas con el presente.

Fotografía Jesús García

Relato-experiencia del autor. 


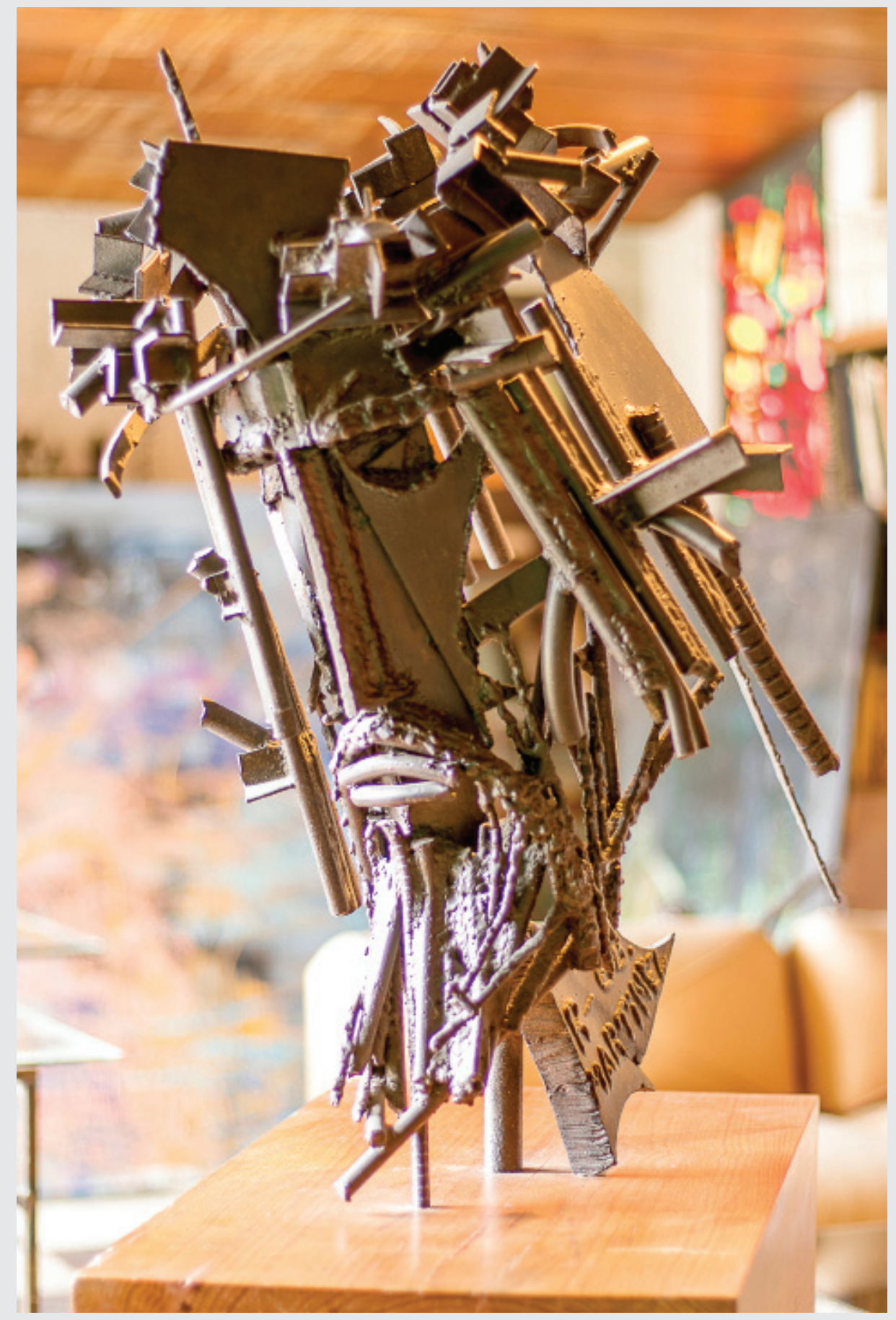

Rubén Martínez Bulnes 